\title{
CANÇÕES MATEMÁTICAS: a apreensão do objeto matemático
}

\author{
MATHEMATICAL SONGS: the approach of math object
}

\author{
Sidcley Dalmo Teixeira Caldas* \\ Adelmo Carvalho da Silva ${ }^{* *}$
}

\section{Resumo}

Este trabalho tem como objetivo geral apresentar o andamento e os "achados" da minha pesquisa de Doutorado, realizada junto ao Programa de Pós-Graduação em Educação - PPGE da Universidade Federal da Bahia - UFBA, cujo objetivo geral é analisar como as canções matemáticas possibilitam o processo de apreensão de objetos matemáticos na escola. Meu interesse pela temática é por ter vivenciado práticas educativas similares, bem como por achar importante analisar como essa estratégia didática contribui no processo de apreensão do objeto matemático, enquanto um tipo de registro de representação semiótica. De abordagem qualitativa, a pesquisa é uma etnopesquisa-formação, na qual serão utilizadas entrevistas semiestruturadas e grupos dialógico-cancionais para a coleta de informações. Serão abordados os teóricos que já dão suporte à investigação, dos quais destacamos Macedo (2004;2012), Garnica (2014), Duval (2009; 2011; 2013a; 2013b), Caldas (2013; 2016a; 2016b) e Tatit (2004; 2008; 2016). Os achados ainda se concentram nos suportes literários, haja vista que o contato com os sujeitos ainda está por acontecer.

Palavras-chave: Canções matemáticas. Apreensão do objeto matemático. Semiótica.

\begin{abstract}
This paper aims to present the progress and findings of my $\mathrm{PhD}$ research, conducted by the Graduate Program in Education - PPGE of the Federal University of Bahia - UFBA, whose general objective is to analyze how mathematical songs enable the process of apprehension of mathematical objects in school. My interest in the subject is to have experienced similar educational practices, as well as to find it important to analyze how this didactic strategy contributes to the process of apprehension of the mathematical object, as a kind of register of semiotic representation. From a qualitative approach, the research is an ethno-research-formation, in which semi-structured interviews and dialogical-song groups will be used to collect information. The theories that already support the research will be addressed, such as Macedo (2004; 2012), Garnica (2014), Duval (2009; 2011; 2013a; 2013b), Caldas (2013; 2016a; 2016b) and Tatit (2004; 2008; 2016). The findings still focus on literary supports, given that contact with the subjects is yet to happen.
\end{abstract}

Keywords: Mathematical songs. Seizure of the mathematical object. Semiotics.

\footnotetext{
Mestre em Educação e Doutorando em Educação pela Universidade Federal da Bahia (UFBA). E-mail: sidcley.caldas@ hotmail.com

** Doutor em Educação pela Universidade Federal da Paraíba (UFPB). Docente do Programa de PósGraduação em Educação da Universidade Federal do Mato Grosso. E-mail: adelmoufmt @ gmail.com
} 


\section{Introdução}

A canção é um dos diversos tipos de manifestação artística. Como tal, possibilita o acesso ao sensivel, às sensações do corpo, tão restritas no atual contexto contemporâneo. Quando, então, ela se faz presente no âmbito escolar, como prática educativa, demonstra a possivel existência de um esforço pedagógico sensivel. Contudo, nem sempre há uma ação docente intencional, consciente e clara, que busca aliar aspectos didáticos com os de natureza sensivel relacionados a esse tipo de atividade. Quando isso acontece, pode-se dizer que está presente, aí, uma didática sensível (D’ÁVILA, 2016).

Embora seja vista como muito importante para o processo de ensino e aprendizagem da matemática, por futuros professores dos anos iniciais do ensino fundamental (CALDAS, 2016a), a presença de canções relacionada à educação matemática gera questões diversas, como relacionadas à efetividade do aprendizado dos conteúdos matemáticos e até como acusações acerca de uma descomprometida prática educativa. Parte da desconfiança que cerca a presença de canções na educação matemática pode ser analisada por dois aspectos: um, pelo fato de se acreditar, ainda, que o foco da educação matemática recaia sobre o objeto matemático em situações de ensino e aprendizagem e, o outro, pela pouca importância ainda destinada às atividades que remetem ao lúdico, ao estético, ao sensivel.

Ainda que a Educação Matemática não se detenha apenas ao objeto matemático, o que ainda causa muito estranhamento, seja entre profissionais desta área ou não, a busca pela compreensão dos processos de ensino e aprendizagem é recorrente e de importância fundamental. Nesse sentido, é natural que se deseje descobrir se/como ocorre o aprendizado de conteúdos matemáticos mediante o contato com canções. 
Canções matemáticas: a apreensão do objeto matemático

Segundo a Teoria dos Registros de Representação Semiótica (TRRS), que integra a tendência matemática conhecida como Didática Francesa, é imperioso que ocorra o trânsito entre ao menos dois tipos de registros de representação para que ocorra a efetiva apreensão do objeto matemático (DUVAL, 2009). No entanto, um dos grandes obstáculos para que isso ocorra é quando um dos registros é o da língua natural, centro da ação educativa (DUARTE JR., 2010), tão presente nos enunciados matemáticos. A canção, por se caracterizar pela união da palavra e da melodia (TATIT, 2008), até possui semelhanças com a lingua natural, mas, por possuir particularidades específicas, não se confunde com ela. Porém, a TRRS não contempla discussões acerca da canção ser classificada como um dos tipos de registro de representação semiótica (língua natural, expressões algébricas, tabelas, gráficos, etc.) e, por consequência, não discute a apreensão de objetos matemáticos mediante a presença de canções nos processos de ensino e aprendizagem de matemática.

Mesmo possuindo aproximações com a língua natural, chama a atenção o fato de que, às vezes, a melodia da canção oculte o que as palavras queiram dizer (SCHAFER, 2011), como se fosse um abandonar do pensar (ROSSI, 2003), como que uma supremacia momentânea do sensível em relação ao inteligivel. Por outro lado, pode acontecer o inverso, com a canção possuindo um maior valor na força entoativa, na intenção do dizer, minimizando os aspectos musicais (TATIT, 2016). Claro que, ainda assim, as possiveis conotações não garantem a devida inteligibilidade da ideia a ser passada. Essa variação entre os limites da canção nem sempre são manipuláveis ou passíveis de controle, o que representa um obstáculo tanto para quem deseja atuar num extremo ou no outro. O desconhecimento de como isso pode afetar a apreensão dos objetos matemáticos é um complicador para que se possa implementar canções durante o processo de ensino e aprendizagem da matemática. 
Considerando o que foi até aqui abordado e visando preencher as lacunas apontadas, questiono: Como as canções matemáticas possibilitam o processo de apreensão de objetos matemáticos na escola?

Destacamos a importância desse trabalho por buscar responder questões relacionadas a uma prática da educação matemática pouco investigada e que ainda não fornece respostas sobre como lidar com a sua implementação, de forma clara e com a devida propriedade.

Sua relevância recai sobre o fato de não existiram pesquisas similares segundo consulta feita no banco de teses da Coordenação de Aperfeiçoamento de Pessoal de Nivel Superior (CAPES), até o momento. Num artigo publicado ainda 2017, por exemplo, no qual se faz o estado da arte acerca da Teoria dos Registros de Representação Semiótica na Educação Matemática, compreendendo o periodo de 2010 a 2015, apenas 6 trabalhos tratam da linguagem natural, das funções discursivas, tema que mais se aproxima da discussão a ser abordada na pesquisa em questão. Foram pesquisados 65 trabalhos nas bases de dados da CAPES, da Biblioteca Digital e Teses e Dissertações - BDTD, assim como em outras instituições. Já acerca de temáticas envolvendo o termo canção, em estudos na educação matemática, Caldas (2016a) apresenta alguns achados, ainda válidos para o atual contexto, confome quadro 1 abaixo. Dos últimos três Encontros Nacionais em Educação Matemática, menos de $1 \%$ dos trabalhos trataram de canções.'

Entendemos que esta investigação se justifica, também, por contribuir para futuras pesquisas correlacionadas com a temática abordada, bem como para subsidiar melhorias no processo de ensino e aprendizagem da matemática na educação básica. 


\section{Objetivos e referencial teórico}

O objetivo geral é analisar como as canções matemáticas possibilitam o processo de apreensão de objetos matemáticos na escola. Como objetivos específicos: investigar como as fronteiras da canção (musical e linguística) influenciam a apreensão de objetos matemáticos; analisar como a conjunção Sensivel $x$ Inteligivel influencia a apreensão de objetos matemáticos; e verificar como a canção se caracteriza enquanto um Registro de Representação Semiótica.

\section{Quanto à canção}

A canção é uma extensão da fala e resultante do entrelace da melodia com a letra. Essa junção é a responsável pelos sentimentos despertados em nós ao ouvir uma canção. Nela, algo é dito de certa maneira, esta, representada pela melodia, enquanto o algo é representado pelas letras das canções, pelos conteúdos presente no seu corpo textual (TATIT, 2004; 2008). Neste cruzamento, encontra-se a linguagem da canção, uma linguagem híbrida, a linguagem verbal-sonora. A fala que se engendra em música ou a música engendrando-se na fala. (SANTAELLA, 2005). Antes de explorarem seus universos particulares os componentes musical e linguístico precisam satisfazer suas necessidades de integração mútua (TATIT, 2016).

Na canção, lidamos, no contexto da expressão, com os binômios opostos palavra-ideia e voz-emoção. Enquanto a palavra é, em essência, a expressão de um pensamento ou ideia, a voz é a expressão de uma emoção. Nesse sentido, a música atua na distensão entre o afetar e o pensar. $O$ fato de afetar se opor ao pensar remete para essa separação entre o intelecto e a afetividade (BUGALHO, 2001; ROSSI, 2003). 
Chamam a atenção os papéis desempenhados tanto pela letra quanto pelo som, os quais podem variar enormemente, podendo o som cumprir o papel de mero acompanhante da letra até quando e, por outro lado, a letra não passar de trampolim para a exploração timbrística da voz como instrumento. Pode acontecer deste extremo atingir uma tal radicalidade que, de sonoro-verbal, a linguagem retornar ao seu estatuto sonoro, sem cruzamento com o verbal oral (SANTAELLA, 2005).

Esses dois extremos podem ser concebidos como limites do cancional. Um residindo na exacerbação da força entoativa, da intencionalidade do dizer, em detrimento da estruturação musical, levando, em última instância, à palavra falada enquanto tal, sem música. O limite oposto seria aquele em que a forma musical possui um valor exclusivo: a mensagem da letra, desprezada, cederia lugar à livre exploração rítmica harmônica, timbrística etc., numa peça musical e não mais numa canção. Exemplos de formas cancionais de fronteira, que residem próximas a esses limites, são o rap e a bossa nova. O primeiro desativa diversos parâmetros musicais para melhor se aproximar da linguagem oral, enquanto o gênero brasileiro dilui a densidade conteudista da letra para se aproximar da linguagem musical. Ambos, porém, evitam ultrapassar os limites da linguagem cancional. Já que, conjuntamente, constituem modos de dizer produzidos pelo encontro entre melodia e letra (TATIT, 2016).

\section{Quanto às canções matemáticas}

Mesmo que diversas práticas com canções ainda carreguem o ideal utilitarista (visando somente a memorização ou como pano de fundo para algum outro tipo de atividade), sem o direito ao prazer, à emoção e à imaginação (DUARTE JR., 2010), outras, no entanto, visam o favorecimento do processo motivacional e perceptivo, além de possibilitar o aumento da autoestima dos mesmos, considerando o impacto, tanto psicológico, como afetivo e social. 
Quando as situações didático-pedagógicas envolvem atividades musicais, a maioria dos alunos demonstram uma relação afetiva com as mesmas, diferentemente do que geralmente ocorre com a Matemática (CUNHA, 2006). Segundo Huizinga (2003), tudo o que se apresenta relacionado à música está situado dentro da esfera lúdica e que, dessa maneira, como o jogo, a música situa-se fora da sensatez da vida prática, sem possuir relação alguma com a necessidade ou utilidade, com o dever ou com a verdade.

A presença de canções na comunicação dos conteúdos matemáticos vem ocorrendo como mais uma estratégia para atrair a atenção dos alunos. Sejam relacionadas à identificação dos conteúdos conceituais, procedimentais e atitudinais (CALDAS, 2013), valorizando o suporte linguístico das canções, sejam à ludicidade (CALDAS, 2016b), as canções que abordam conteúdos matemáticos em suas letras (canções matemáticas) apresentam algumas características quando presentes no processo de ensino e aprendizagem. Caldas (2016a) faz algumas observações quanto a isso, destacando algumas vantagens e desvantagens que vão além das qualidades específicas dessa prática, mas, também, que se relacionam à sua apropriação pelo professor, se assemelhando, assim, com diversos outros recursos de ensino.

Caldas (2016a) destaca a diminuta quantidade de pesquisas que envolvem a presença de canções que abordam conteúdos matemáticos. Seu trabalho investigativo demonstrou que futuros professores dos anos iniciais do Ensino Fundamental possuem a crença de que esse tipo de canção pode contribuir no processo de ensino e aprendizagem da matemática, principalmente por apresentar um caráter lúdico. No entanto, não foram verificadas argumentações que especificassem, de forma mais clara, como aconteceria a aprendizagem sugerida, o que, ainda, requer maiores debates acerca de sua efetiva contribuição para a apreensão dos objetos matemáticos. Apesar de não analisar a linguagem cancional, os estudos de Cavalcanti (2011) apontaram indícios de que a composição de 
paródia musical atribuiu melhoras na aprendizagem do conteúdo circunferência. Nesse sentido, cabe lembrar que a paródia também é canção, haja vista que contempla os suportes melódicos e linguísticos, ao mesmo tempo.

\section{Quanto à Educação Matemática}

Na visão de Fiorentini e Lorenzato (2009), Nunes (2012), a Educação Matemática é uma área de conhecimento das ciências sociais ou humanas, relacionada às mais variadas áreas do conhecimento, como a Filosofia, a própria Matemática, a Psicologia, a Sociologia, a Linguística, a Epistemologia, a Semiótica e a Antropologia, entre outras. Caracteriza-se como uma práxis que envolve tanto o domínio do conteúdo específico, os objetos matemáticos, quanto o domínio de ideias e processos pedagógicos relativos ao saber matemático escolar. Bicudo e Borba (2012), e Oliveira e Marim (2014), ao teorizarem sobre o assunto, afirmam que atualmente, a Educação Matemática contempla diversas tendências, como Modelagem Matemática, Etnomatemática, Filosofia da Educação Matemática, Matemática Crítica, Resolução de Problemas, Didática da Matemática, Jogos em Educação Matemática, entre tantas outras (BICUDO \& BORBA, 2012; OLIVEIRA \& MARIM, 2014).

Garnica (2014) defende que a análise dos trabalhos em Educação Matemática somente voltada para o objeto matemático em situações de ensino e aprendizagem não faz sentido. Diferentemente, afirma que há que se dialogar com outras áreas do conhecimento, independente de que, por algum momento, o objeto matemático venha parecer diluir-se. No entanto, essa diluição não viria a significar a morte da Matemática, nas investigações em Educação Matemática, mas, sim, um caminho para que seja realizado um efetivo diálogo interáreas, indispensável para sua própria caracterização como área, cujo objeto é interdisciplinar. 


\section{Quanto à apreensão dos objetos matemáticos}

A teoria dos registros de representação semiótica, integrante das concepções teóricas que formam a Didática Francesa, se baseia na pluralidade de representação de um mesmo objeto matemático e, principalmente, na articulação desses diferentes registros como condição necessária para a compreensão em matemática. Para o autor dessa teoria, o grande equívoco teórico, metodológico do ensino de matemática e da maioria das pesquisas em didática é acreditar que as produções verbais ou escritas dos alunos, que são fenômenos de superficie, refletiriam direta e imediatamente o funcionamento cognitivo multirregistro do pensamento matemático (DUVAL, 2013a; 2013b).

Para Duval (2013a; 2013b), não existe acesso perceptivo, direto ou instrumental aos objetos matemáticos (números, funções, etc.). Para acessar esses objetos, do ponto de vista cognitivo, a atividade matemática deveria ser analisada em termos de transformações de representações semióticas e não de conceitos puramente mentais, e, portanto, assemióticos. No entanto, lembra que o objeto matemático nunca deve ser confundido com a representação semiótica utilizada para representá-lo. Esta condição gerou o paradoxo cognitivo da matemática: se não temos acesso ao próprio objeto, fora de sua representação, então como não o confundir com ela? Porém, o que permite contornar esse paradoxo é a possibilidade de multirrepresentação potencial de um mesmo objeto. A única opção para não confundir o conteúdo de uma representação com o objeto representado é dispor de ao menos dois registros de representação diferentes.

Dois conceitos são importantes para o entendimento da teoria posta. Um é o de tratamento, uma transformação interna a um registro de representação ou a um sistema, como adicionar dois números fracionais ou subtrair dois números decimais. O outro é o de conversão, uma transformação externa ao registro da representação de partida, conservando a 
totalidade ou, apenas, uma parte do objeto matemático em questão. Como exemplos, a passagem da escrita algébrica de uma equação à sua representação gráfica e de uma representação linguística em uma representação figural. No entanto, a conversão se configura como uma das maiores dificuldades dos alunos na compreensão em matemática. Ainda, quando um dos registros é um registro plurifuncional, como o da língua natural, a situação se torna ainda mais complexa (DAMM, 2012; DUVAL, 2009; 2013b).

A língua constitui o primeiro registro de representação semiótica para o funcionamento do pensamento e se destaca por sua maior complexidade e de sua prioridade genética sobre os outros registros. Além disso, cumprem, ao mesmo tempo, funções tanto de comunicação como cognitivas. Quando de comunicação, a consideramos como códigos, já quando cognitivas, como registros. Entretanto, existe uma distância cognitiva considerável entre a lingua natural e os outros registros, o que torna dificil a conversão dos enunciados da língua natural para representações em outro registro. Tanto que a origem das dificuldades na resolução dos problemas aditivos, por exemplo, deve ser procurada prioritariamente no nível da compreensão do enunciado, já que as dificuldades não se referem aos aspectos numéricos e pragmáticos, mas na compreensão das relações de ordem temporal, indicadas no enunciado e no sentido dos verbos portadores de uma informação numérica, como tem, perde, ganha, etc. Dessa forma, a fim de evitar esse tipo de obstáculo, deve-se recorrer às representações auxiliares de transição, ao converter o registro da língua num outro tipo de representação (DAMM, 2013; DUVAL, 2011).

\section{Metodologia}

A pesquisa terá abordagem qualitativa, uma etnopesquisa-formação (MACEDO, 2012), flertando epistemologicamente com a fenomenologia. O processo investigativo acontecerá durante os próximos quatro anos (2018 a 2021). Como grupo pesquisado, uma turma do $4^{\circ}$ ano dos anos iniciais 
do Ensino Fundamental, numa escola pública de Salvador, a ser escolhida durante o processo de investigação. A escolha pelo ano especificado é devido aos seguintes motivos: ao fato do acompanhamento ocorrer durante dois anos (2019 e 2020), sendo que no segundo ano os alunos, já no $5^{\circ}$ ano, terão visto grande parte dos quatro blocos de conteúdos matemáticos devidos (números e operações, espaço e forma, grandezas e medidas e tratamento da informação); pela facilidade deste pesquisador em acessar ambientes escolares referentes ao período do $1^{\circ}$ ao $5^{\circ}$ ano; e pela melhor aceitação dos atores educativos quanto à implementação deste tipo de prática investigativa.

O caminho metodológico será construído, inicialmente, com leituras de textos integrantes da literatura previamente levantada e, simultaneamente, pesquisa de novas fontes, que contribuam para o desenvolvimento dos trabalhos. Contemplará a análise documental, a observação, entrevistas semiestruturadas e a utilização de grupos dialógico-cancionais (CALDAS, 2016a), para a identificação das compreensões e relações elaboradas acerca da temática discutida.

Nos grupos dialógico-cancionais, ocorrerão discussões acerca do tema em questão, incluindo a exibição de vídeos, áudios e execuções instrumentais de canções que abordem conteúdos matemáticos da educação básica. Neles, os participantes não irão, apenas, dialogar sobre fatos descritos ou exibidos. Eles irão, também, participar de práticas sobre as quais apresentarão compreensões e suscitarão, assim, compreensões acerca de suas compreensões.

Seja cantando, dançando, ouvindo canções ou tocando instrumentos musicais, os sujeitos estarão envolvidos em práticas que possivelmente podem levá-los a relacionar esses momentos com outros já experenciados. Ou seja, os diálogos serão expressos além das entoações naturais da fala. Serão complementados e/ou, talvez, potencializados por ações deri- 
vadas do contato com as músicas e as canções. Serão feitos encontros durante os dois anos de imersão ao campo de pesquisa, com duração de 1 h cada. Serão feitos 16 (dezesseis) encontros, no total, sendo que 8 (oito) por ano, e 4 (quatro) por cada grupo da turma (esta, dividida em dois grupos, com a mesma quantidade de alunos). Para o registro desses momentos, utilizarei um gravador digital da marca Sony, modelo ICD-PX312 2GB.

Enfim, após a coleta de informações, reagruparei os enunciados em noções subsunçoras (MACEDO, 2004), para, em seguida, iniciar as devidas análises.

\section{Referências}

BICUDO, Maria Aparecida Viggiani; BORBA, Marcelo de Carvalho (Orgs.). Educação Matemática: pesquisa em movimento. São Paulo: Cortez, 2012.

BUGALHO, Sérgio. O poema como letra de canção. In: MATOS, Cláudia Neiva de; TRAVASSOS, Elizabeth; MEDEIROS, Fernanda Teixeira de (Orgs.). Ao encontro da palavra cantada: poesia, música e voz. Rio de Janeiro: 7Letras, 2001. p. 299-308.

CALDAS, Sidcley Dalmo Teixeira. A presença de canções na Educação Matemática: compreensões de futuros professores dos anos iniciais do ensino fundamental. 2016. 140 f. Dissertação (Mestrado em Educação) Programa de Pós-Graduação em Educação, Faculdade de Educação, Universidade Federal da Bahia, Salvador, 2016a. 
CALDAS, Sidcley Dalmo Teixeira. As canções nos diálogos matemáticos: buscando a ludicidade. In: ENCONTRO NACIONAL DE EDUCAÇÃO MATEMÁTICA, 12., 2016, São Paulo. Anais... São Paulo: UNICSUL, 2016b.

. O uso de canções no ensino-aprendizado da Matemática: identificando os conteúdos conceituais, procedimentais e atitudinais. ENCONTRO NACIONAL DE EDUCAÇÃO MATEMÁTICA, 11., 2013, Curitiba. Anais... Curitiba: PUCPR, 2013.

CAVALCANTI, Valdir de Sousa. Composição de paródias: um recurso didático para compreensão sobre conceitos de circunferência. Campina Grande: UEPB, 2011. 163f. Dissertação (Mestrado em Ensino de Física) Universidade Estadual da Paraíba, Campina Grande, 2011.

CUNHA, Nilton Pereira da. Matemática \& música: diálogo interdisciplinar. Recife: Ed. Universitária da UFPE, 2006.

DAMM, Regina Flemming. Registros de representação. In: MACHADO, Silvia Dias Alcântara (Org.). Educação matemática: uma (nova) introdução. São Paulo: EDUC, 2012.

- Representação, compreensão e resolução de problemas aditivos. In: MACHADO, Silvia Dias Alcântara (Org.). Aprendizagem em matemática: registros de representação semiótica. Campinas: Papirus, 2013.

D’ÁVILA, Cristina Maria. Razão e sensibilidade na docência universitária. In: Revista Em Aberto, Brasília, v. 29, n. 97, p. 103-118, set./dez. 2016.

DUARTE JR., João-Francisco. A montanha e o videogame: escritos sobre educação. Campinas, SP: Criar Edições, 2010. 
DUVAL. Raymond Duval e a teoria dos registros de representação semiótica. Revista paranaense de educação matemática - RPEM. Campo Mourão: Universidade Estadual do Paraná, v. 2, n. 3 (jul. /dez.2013), 2013a. Entrevista concedida a José Luiz Magalhães de Freitas

- Registros de representação semióticas e funcionamento cognitivo da compreensão em matemática. In: MACHADO, Silvia Dias Alcântara (Org.). Aprendizagem em matemática: registros de representação semiótica. Campinas: Papirus, 2013b.

. Semiósis e pensamento humano: registro semiótico e aprendizagens intelectuais. São Paulo: Livraria da Física, 2009.

. Ver e ensinar a matemática de outra forma: entrar no modo matemático de pensar: os registros de representações semióticas. (Organização Tânia M. M. Campos). São Paulo: PROEM, 2011.

FIORENTINI, Dario; LORENZATO, Sergio (Orgs.). Investigação em educação matemática: percursos teóricos e metodológicos. Campinas, SP: Autores Associados, 2009. (Coleção formação de professores)

GARNICA, Antonio Vicente Marafioti. Matemática, educação matemática, cidades e casacos vermelhos: um prefácio. In: OLIVEIRA, Cristiane Coppe de; MARIM, Vlademir. Educação matemática: contextos e práticas docentes. Campinas, SP: Editora Alínea, 2014.

HUIZINGA, Johan. Homo ludens: o jogo como elemento da cultura. São Paulo: Perspectiva, 2003.

MACEDO, Roberto Sidnei. A etnopesquisa critica e multirreferencial nas ciências humanas e na educação. Salvador: EDUFBA, 2004. 
MACEDO, Roberto Sidnei. A etnopesquisa implicada: pertencimento, criação de saberes e afirmação. Brasília: Liber Livro Editora, 2012.

NUNES, Célia Barros. A educação matemática na UNEB/Campus X. In: NUNES, Célia Barros; SANT'ANA, Claudinei Camargo; SANTANA, Erivalda Ribeiro dos Santos. Educação Matemática na Bahia: panorama atual e perspectivas. Vitória da Conquista: Edições UESB; Itabuna: Via Litterarum Editora, 2012.

OLIVEIRA, Cristiane Coppe de; MARIM, Vlademir. Educação Matemática: contextos e práticas docentes. Campinas, SP: Editora Alínea, 2014.

ROSSI, Deise Mirian. O amor na canção: uma leitura semióticopsicanalítica. São Paulo: EDUC; Casa do Psicólogo; FAPESP, 2003.

SANTAELLA, Lucia. Matrizes da linguagem e pensamento: sonora visual verbal. São Paulo: Iluminuras: FAPESP, 2005.

SCHAFER, R. Murray. O ouvido pensante. São Paulo: UNESP, 2011.

TATIT, Luiz. Elos de melodia e letra: análise semiótica de seis canções. Cotia, SP: Ateliê Editorial, 2008.

- Estimar canções: estimativas íntimas na formação do sentido. Cotia, SP: Ateliê Editorial, 2016.

. O século da canção. Cotia: Ateliê Editorial, 2004.

Artigo recebido em: 31 out. 2019 Aprovado em: 20 nov. 2019 